\title{
LIFE SCIENCES TEACHERS' CONCEPTIONS ABOUT SOCIOSCIENTIFIC ISSUES IN THE TOPIC EVOLUTION
}

\author{
Mokgadi Relela, \& Lydia Mavuru \\ Department of Science and Technology Education, University of Johannesburg (South Africa)
}

\begin{abstract}
The goal of science education is emphatically positioned on promoting science literacy. The rationale is learners should not only learn about scientific knowledge and processes but also on how to apply the knowledge when making decisions about heterogenous societal and personal issues. Previous research has indicated that by addressing socioscientific issues (SSIs) when teaching controversial science topics, it provides a suitable context for developing scientific literacy in learners. Scientifically literate learners are well-informed citizens with regards to the social, ethical, economic, and political issues impacting on contemporary society. The theory of evolution is one such Life Sciences topic deeply embedded with SSIs. Teachers are conflicted when teaching this topic due to the controversy surrounding the theory as they view the teaching of evolution as a way of negating the legitimacy of their religious and cultural convictions. It is against this background that the study sought to answer the research question: How do Life Sciences teachers conceptualise socioscientific issues embedded in the topic evolution? In an explanatory mixed method approach, a questionnaire with both quantitative and qualitative questions was administered to 28 randomly selected grade 12 Life Sciences teachers. Data was analysed and descriptive statistics were obtained, and themes generated. The findings showed that all the participants were knowledgeable about the SSIs embedded in the topic evolution. In justifying their conceptions $61 \%$ of the teachers perceived SSIs as important in improving learners' reasoning and argumentative skills; developing learners' critical thinking skills; and in informing learners in decision making. There were however $11 \%$ of the teachers who pointed out that SSIs as too sensitive to deal with hence not suitable to teach young learners. Though the teachers were knowledgeable about the SSIs embedded in the theory of evolution, it does not mean that they could address them when teaching the various concepts of evolution. The main source of the controversy rose from the evolution of humankind versus the Christian belief in the six-day special creation. The participants (25\%) indicated that evolution challenges peoples' religious and cultural convictions, which conflicts both the teachers and learners to question or go against their religious beliefs. Several teachers pointed out that some of the concepts on evolution such as 'living organisms share common ancestry (18\%) and 'the formation of new species from existing species' (11\%), undermine the superiority of human beings over other organisms. The findings have implications for both pre-and in-service teacher professional development.
\end{abstract}

Keywords: Evolution, life sciences, socioscientific issues.

\section{Introduction}

Achieving science literacy is a fundamental objective in the advancement of science education. Science literacy can be achieved by engaging learners in debates, dialogues, discussion, and argumentation, which requires learners to justify the claims they make with reasons and evidence (Zeidler, 2014). Such achievements can be done through the integration of science and society whilst teaching topics that are entangled with controversial issues (Janasoff, 2010). Topics such as the theory of evolution, climate change and cloning are spelled out as being embedded with socioscientific issues (SSIs) (Janasoff, 2010). Addressing SSIs has been positioned as an effective way for learners to contextualize their science learning within a challenging social and political background (Hancock, Friedrichen, Kinslow, Sadler, 2019). To date research has clearly indicated that by addressing SSIs when teaching controversial science topics provides a well-suited approach for developing science literacy (Hancock et al., 2019). The theory of evolution is a topic embedded with SSIs and, if adequately addressed in the manner which is commensurate with its significance as a fundamental building block of life and its overall explanatory power in the Life Sciences classrooms, it can increase learners' levels of science literacy needed to prepare them for careers in Science, Technology, Engineering, and Mathematics (STEM) (National Science Teachers' Association, 2013).

Previous researchers have documented the antagonism between religious and cultural views and the theory of evolution as the main stumbling block in the teachers' and learners' willingness to engage with the concepts on the theory of evolution in the Life Sciences/Biology classrooms. The argument is that science instruction on the theory of evolution has the tendency to a certain extent to impact 
negatively on learners' socio-cultural values as it compels them to invalidate their indigenous values (Deniz \& Borgerding, 2018). As such, Weiland (2015) advocates for culturally relevant pedagogy which affords learners with modalities designed to ensure the maintenance of their cultural identity whilst ensuring that they are achieving goals academically during the teaching and learning of the theory of evolution. In their arguments for endorsement of the theory of evolution, Berta, Pobiner, Beardsley and Watson (2019) argued that learners may opt to deny the theory of evolution due to their religious and cultural backgrounds, but to be scientifically literate, it is necessary that the Life Sciences learners understand how and why scientists consider the theory of evolution to be the basic building block in Life Sciences. In agreement, Reiss (2019) pointed out that the pivotal role of the Life Sciences teachers is not to convert learners who do not accept the theory of evolution to accept the theory, but to build a sensitive multicultural classroom environment that aims to promote those learners who are most uncomfortable with the theory of evolution to engage in the topic on their own free will. Of utmost importance is for all Life Sciences learners to discover and acknowledge the theory of evolution in a classroom atmosphere that does not compel them to choose between science and their religious and cultural convictions. From this perspectives, pervious science research has advocated for the need to teach the theory of evolution in a classroom atmosphere that acknowledges the religious and cultural controversies surrounding the topic, with the aim of focusing on an increased scientific understanding as opposed to the endorsement of the theory of evolution (Berta et al., 2019; Reiss, 2019).

Religious and cultural discontentment are not the only impediment endangering the teaching and learning of the theory of evolution, the other is teachers' incapacitation to address the socioscientific controversy surrounding the theory (Sutherland \& L'Abbe, 2019). Teachers' capacity to exchange views about socioscientific issues in topics such as the theory of evolution in an efficient approach while at the same time being respectful and sensitive of learners' religious and cultural convictions forms the backbone of democracy (Sutherland \& L'Abbe, 2019).

Chikoko, Gilmour, Harber and Serf (2011) reported that Life Sciences teachers are not capacitated to manage the discussion of controversial issues in their classrooms. Similarly, in a study conducted by Mavuru (2018), findings indicated that Life Sciences teachers expressed their inability to properly address the socioscientific issues surrounding the theory, notably when faced with learners from different socio-cultural and religious convictions, which are perceived as antagonistic to the theory of evolution. Teachers are conflicted when teaching this topic as they view the teaching of evolution as a way of negating the legitimacy of their religious and cultural beliefs. It is against this background that the study sought to answer the research question: How do Life Sciences teachers conceptualise socioscientific issues embedded in the topic evolution?

\section{Literature review}

Several researchers in science education advocate that for the greater benefit of educating future citizens who are familiar with the scientific way of thinking by engaging learners in dialogues, discussion, debate, and argumentation (Zeidler, 2014). This would make learners realise the connections between science and their lives and to make well-informed decisions (Han-Tosunoglu \& Lederman, 2016). This suggests that science teachers are not only required to prepare learners for educational achievement, but to provide an education that nurtures science learners to become citizens who are cognisant of ethical, cultural, political, and economic aspects of the contemporary society (Han-Tosunoglu \& Ledermann, 2016). However, numerous studies on the teaching of controversial topics reported that science teachers find the addressing of SSIs challenging (Han-Tosunoglu \& Irez, 2017). In particular, science teachers are reluctant to use SSIs approach due to the concerns regarding classroom management and their own abilities (Tidemand \& Nielsen, 2017); time constraints linked to the curriculum coverage (Tidemand \& Nielsen, 2017); parental reaction, administrative pressures, and feelings of inadequacy in content areas (Greer \& Glaze, 2016). This is especially true with the most controversial topic in the history of science, which is the theory of evolution. According to Ogunleye (2009), the controversy surrounding the theory of evolution is deeply ingrained in the individuals' perceived antagonism between scientific understanding of the theory and the internal worldviews the individual is affiliated to. Glaze (2018) contends that it is the issue of evolution of humankind, and the emergence of new species, that causes the greatest antagonism among the public.

\section{Methodology}

The study employed an explanatory mixed methods research design (Creswell, 2014). This design was appropriate in combining the strength of both quantitative and qualitative research methods thereby compensating for their individual limitations (Pluye \& Hong, 2014). A group of 28 Life Sciences teachers from diverse socioeconomic and cultural background in terms of race, ethnicity religion was randomly selected. These included 14 teachers from township schools, 8 teachers from suburban schools, 2 from independent schools and four from Christian schools. Of the 28 participants 16 were Christians, 3 were Muslims and 9 identified themselves as following Traditional African religion. The sample was 
suitable for this study due to the high levels of diversity amongst teachers and learners in the schools in terms of values, culture, and ethnicity, which could influence the SSIs teachers hold. The assumption was that the teachers' and learners' religious and cultural backgrounds were likely to influence their instructional practices during the teaching and learning of the theory of evolution.

Data collection involved the administration of an adopted and adapted questionnaire for assessing the Pedagogical Content Knowledge for Biological Socio-scientific Issues (PCK-BSSIs) (Han-Tosunoglu \& Lederman, 2016). The questionnaire consists of two sections, A and B. Section A of the questionnaire required teachers' background information, which is science teaching orientation, while section B of the questionnaire focuses on teachers' understanding/beliefs about SSIs. Teachers' responses of the questionnaire were analysed using a rubric developed by Han-Tosunoglu and Lederman (2016) and descriptive statistics were obtained. The rubric helped to accommodate the responses for each question in one of three different categories: Inadequate understanding, eclectic understanding, and reform-based understanding, that indicate the degree to which participants are familiar with each of the given statements or not. Reform-based understanding indicates an in-depth understanding, or deep knowledge, of the teaching and learning of the theory of evolution. Eclectic understanding signifies that the participants showed some degree of understanding about the teaching and learning of the theory of evolution. While inadequate understanding shows that the participants are not knowledgeable with regards to the teaching and learning of the theory of evolution. In this study, we present the result of Section B of the instrument which is related to teachers' conceptions about the socioscientific issues in the topic evolution.

\section{Research findings}

Teachers' conceptions of socioscientific issues in the topic evolution was measured by five items of Section B of PCK- BSSIs questionnaire. Figure 1 that follows presents findings on the distribution of the participants' conceptions.

Figure 1. Teachers' conceptions about socioscientific issues embedded in the topic evolution.

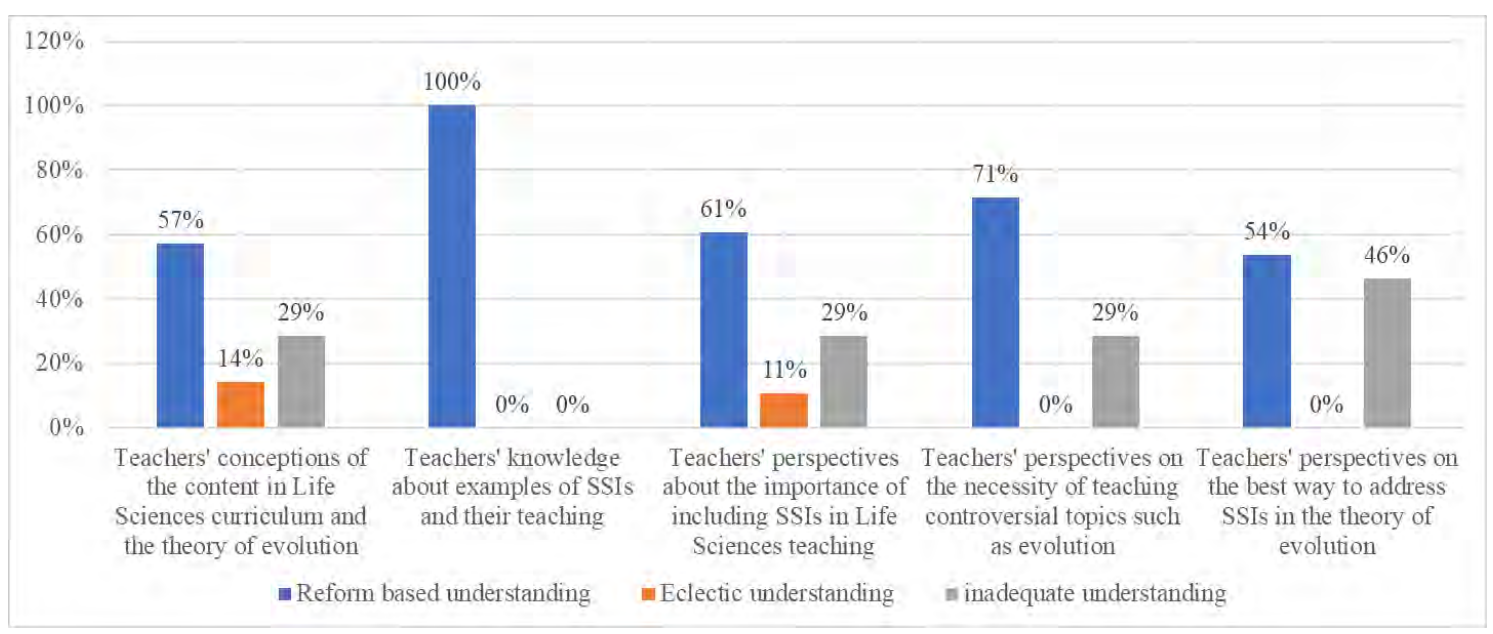

From Figure 1, in the first item which asked the participants about their perspective of the inclusion of the theory of evolution in the Life Sciences curriculum and whether there is potential for conflict between their personal beliefs and scientific beliefs, more than half $(57 \%)$ of the participating teachers perceived themselves as not having any personal conflict with the theory of evolution. As such, they recommended the inclusion of the theory of evolution in the Life Sciences curriculum. The participants' arguments in favour of the inclusion of the theory of evolution in the Life Sciences curriculum were that evolution is the only convincing theory that explains the existence of all living organisms on earth. As deduced from their justification, despite their familiarity with both scientific and religious beliefs, teachers in this category were not concerned that their beliefs about the theory are somehow antagonistic towards their religious beliefs about the special creation, and as such they still felt the topic should be included in the curriculum. On the other hand, $14 \%$ of the participants indicated that the evolution of humankind was inappropriate, hence should not be included as part of the evolution content in the grade 12 Life Sciences curriculum. These teachers particularly pointed out that the evolution of humankind was their bone of contention as it undermines the learners' and their religious and cultural convictions. The teachers in this category in a way indicated that they could easily embrace and acknowledge the fundamental ideas of the theory of evolution, on condition that those ideas are not applicable to the evolution of humankind. About a third $(29 \%)$ showed a lack of understanding about the theory of evolution. This was evident in their reasoning for not supporting the inclusion of the theory in 
the Life Sciences curriculum, which centred on the theory influencing the religious beliefs of the teenagers (grade 12 learners) who are still immature in making decisions for themselves.

All the teachers indicated that they had an in-depth knowledge and understanding of the socioscientific issues surrounding the theory of evolution and the teaching there of as indicated in item 2 . The second item was aimed at revealing teachers' awareness, recognition, and acknowledgement of their learners' socio-cultural background. Teachers' familiarity with the socioscientific issues embedded in the theory of evolution is envisioned to enable them to plan their lessons in a manner that provides learning opportunities relevant and sensitive to their learners' religious and cultural backgrounds. As deduced from their responses, it is the evolution of humankind versus special creation that emerged as the source of most socioscientific controversy surrounding the theory of evolution.

The third item was on the participants' perspectives on the need to address SSIs in their Life Sciences, (not specifically the theory of evolution). The analysis of data showed that more than half of the participants $(61 \%)$ stated that teaching learners about SSIs was crucial. In justifying their conceptions, teachers conceived SSIs as important in improving learners' reasoning and argumentative skills; developing learners' critical thinking skills; and in informing learners in decision making. Teachers in this category showed a reform-based understanding by virtue of acknowledging the values of addressing the SSIs during teaching and learning as a key principle for science literacy. Such a stance is particularly fitting for the South African curriculum, which supports equipping learners with the skills and values necessary for self-fulfillment and, meaningful participation in society as citizens of a free country (Department of Basic Education [DBE], (2011). From that same third item, 11\% of teachers had mixed views, indicating that some of the SSIs should be included while others are overly sensitive to deal with in the Life Sciences classrooms. These participants displayed an eclectic understanding, which means they showed some degree of understanding the need to address the SSIs. These teachers mentioned that the teaching of topics such as the theory of evolution, abortion, stem cell research, and HIV/AIDS, can stir emotions in their learners. In justifying their stance, the teachers pointed out that learners come from diverse sociocultural and religious backgrounds, which makes it difficult to address the diverse SSIs brought in by the learners. $29 \%$ of the teachers showed lack of understanding.

The fourth item was on teachers' conceptions on the need to address controversial and debatable issues on the topic of evolution in Life Sciences classrooms. Analysis of data revealed that most participants $(71 \%)$ presented reform-based understanding in acknowledging that addressing controversial and debatable topics in the Life Sciences classrooms was worth the effort and time. Teachers' reasons for advocating for the address of SSIs were based on the fact that addressing controversial issues would go a long way in developing science literacy among learners. The reason most of the teachers in this category gave for supporting the addressing of SSIs was that learners would become well informed citizens who could reason and argue about any matter at hand. They pointed out that in such a classroom environment, learners are given opportunities to recognize and appreciate different perspectives from their peers during the process of argumentation and debating. Though the teachers acknowledged and advocated for addressing controversial and debatable issues in their Life Sciences classrooms, there were however $11 \%$ of the $71 \%$ who indicated their inability to create learning environments conducive for debate and argumentation in their classrooms. The fear of losing control was the main reason pointed out by these teachers as classroom management is problematic in most South African classrooms in public schools.

Quite the opposite, the findings indicated that $29 \%$ of teachers showed that they lacked knowledge and understanding in addressing SSIs. The lack of understanding is evident in one of the participants who wrote, "debating controversial topics is for Life Orientation classes, not Life Sciences, here we are dealing with content, only." This view is contrary to the vision of science education postulated by Sadler (2004) that learners should not only learn about conceptual knowledge of the subject matter and scientific processes, but also how to use this knowledge for making decisions about complex societal and personal issues learners encounter in their daily lives. Some teachers who showed inadequate understanding argued that "evolution is just a theory", insinuating the theory of evolution as questionable and discreditable.

The last item (fifth item) sought teachers' perspectives on the best way to address the SSIs embedded in the theory of evolution. The item was aimed at revealing the pedagogical strategies employed by Life Sciences teachers during the teaching and learning of concepts in the theory of evolution. The analysis of data showed that there were two main school of thought, regarding the integration of SSIs embedded in the theory of evolution, namely: the first school of thought was categorised by teachers who engage learners in the socioscientific controversy surrounding the theory of evolution and the second school of thought was categorised by teacher who do not engage learners in the socioscientific controversy surrounding the theory of evolution. In this item more than half (54\%) of the participants engaged their learners in controversial activities that develop learners' critical, argumentative, and analytical thinking skills. The participants' reasons for engaging learners in controversy is that it allows their learners to become independent thinkers who are well informed. The participants indicated that this approach allows their learners to explore and establish a relationship between their existing knowledge and the new scientific knowledge. They also indicated that no learner would be left out or 
marginalized as their ideas would be embraced and acknowledged during discussions. Teachers also pointed out that misconceptions that may arise, will be addressed accordingly.

In this item, $46 \%$ of teachers indicated that they do not engage their learners in the discussions of socioscientific controversy surrounding the topic. These teachers pointed out that such discussions create conflict with their learners' religious and cultural backgrounds. This implies that these teachers were not well capacitated to facilitate discussions of the socioscientific issues in their classrooms. An important point raised by these teachers was that the topic is too long, and the time allocated for the teaching and learning of the theory is too little to allow discussions. Failure to complete the teaching of this topic would compromise learners' performance in their final examinations as the topic constitutes $44 \%$ of the marks in Paper 2.

\section{Discussion}

The findings showed that majority of the Life Sciences teachers categorised as having reform-based understanding, were deeply knowledgeable of their own as well as the learners' religious and cultural backgrounds. They accommodated and embraces in their pedagogical instructions. This is in accord with Berta et al. (2019) assertion that for most learners, acknowledging religious and cultural challenges associated with the theory is an effective classroom strategy for creating supportive classroom atmosphere. Previous studies (e.g. Berta et al., 2019; Reiss, 2019) underscore that in Life Sciences classrooms where learners hold religious and cultural worldviews that may interfere with the understanding of the theory of evolution, learners are highly unlikely to understand the theory until such time that their religious and cultural concerns are addressed.

\section{Conclusion and implications}

The findings of this study reinforce the need for Life Sciences teachers to consider the goals of science education which are aimed at producing science literate learners who are well-informed citizens by addressing SSIs embedded in topics such as the theory of evolution. Some of the teachers indicated that they address SSIs by engaging learners in debates, dialogues, discussion, and arguments. There were teachers who showed a lack of understanding of the importance of addressing SSIs as their focus was on completing the curriculum and preparing learners for examinations. There were some who did not support the inclusion of the theory of evolution in the curriculum arguing that the theory undermines the learners sociocultural and religious beliefs, particularly the evolution of humankind.

\section{References}

Bertka, C.M., Pobiner, B., Beardsley, P., \& Watson, W.A. (2019). Acknowledging students' concerns about evolution: a proactive teaching strategy. Evolution: Education and Outreach, 12(1), 3.

Chikoko, V., Gilmour, J.D., Harber, C. \& Serf, J. (2011). Teaching controversial issues and teacher education in England and South Africa. Journal of Education for Teaching, 37(1), 5-19.

Deniz, H. and Borgerding, L.A. (2018). Evolutionary theory as a controversial topic in science curriculum around the globe. In Evolution education around the globe (3-11). Springer, Cham.

Glaze, A. (2018). From worldviews to classrooms: Framing evolution acceptance in pre-service science teachers in the southeastern United States. Georgia Educational Researcher, 14(2), 1-12.

Greer, K. and Glaze, A. (2016). Socio-Scientific Argumentation as a Driver for Science Learning. New Perspectives in Science Education 5. 10.13140/RG.2.2.14176.28160.

Hancock, T. S., Friedrichsen, P. J., Kinslow, A. T., \& Sadler, T. D. (2019). Selecting socio-scientific issues for teaching. Science \& Education, 28(6-7), 639-667.

Han-Tosunoglu, C., \& Lederman, N. G. (2016). The development of an instrument for assessing pedagogical content knowledge for socioscientific knowledge (PCK-SSI). National Association for Research in Science Teaching (NARST). Baltimore, USA.

Mavuru, L. (2018). Teaching Evolution to Grade 12 Learners: Teachers' views and pedagogical practices. In M. Carmo (Ed.) Education Applications \& Developments IV: Advances in Education and Educational Trends Series (pp. 148-158). Portugal: In Science Press. http://hdl.handle.net/10210/274375

National Science Teachers Association (2012). NSTA standards for science teacher preparation.

Reiss, M. J., 2019. Evolution education: treating evolution as a sensitive rather than a controversial issue. Ethics and Education, 14(3), 351-366.

Sutherland, C. \& L'Abbé, E.N. (2019). Human evolution in the South African school curriculum. South African Journal of Science, 115(7-8), 1-7.

Tidemand, S. \& Nielsen, J.A. (2017). The role of socioscientific issues in biology teaching: From the perspective of teachers. International Journal of Science Education, 39(1), 44-61.

Zeidler, D.L. (2014). Socioscientific issues as a curriculum emphasis. Theory, research, and practice. In NG Lederman \& SK Abell (Eds.). Handbook of research on science education, 2, 697-726. 